ИЗВЕСТИЯ АКАДЕМИИ НАУК ЭСТОНСКОП ССР. ТОМ 32 ХИМИЯ. 1983, № 3

\title{
ИЗУЧЕНИЕ КИНЕТИКИ ТРАНСФОРМАЦИИ И ПРОЦЕССОВ СОРБЦИИ ХЛОРОРГАНИЧЕСКИХ ПЕСТИЦИДОВ И ПОЛИХЛОРИРОВАННЫХ БИФЕНИЛОВ ПРИ ХРАНЕНИИ ПРОБ ВОДЫ
}

O. ROOTS. POLOKLOREERITUD BIFENOOLIDE JA KLOORORGAANILISTE PESTITSIIDIDE LAGU. NEMISE KINEETIKA JA SORPTSIOONIPROTSESSID VEEPROOVIDES

O. ROOTS. STUDY OF POLYCHLORINATED BIPHENYLS AND CHLORORGANIC PESTICIDES DECOMPOSITION AND SORPTION PROCESSES IN WATER SAMPLES

\section{(Представил О. Эйзен)}

Разложение загрязняющих веществ в естественной среде в основном происходит либо с участием микроорганизмов, либо путем физикохимического окисления ['].

Исследование кинетики трансформации хлорорганических углеводородов проводили путем лабораторного моделирования. Остановились при этом на трех температурных режимах $-0-1^{\circ}, 6-8^{\circ}$ и $20-22^{\circ} \mathrm{C}$ - как наиболее соответствующих климатическим особенностям Балтийского моря. Среднегодовая температура поверхностных вод в Балтике убывает с юга на север: у Готланда она равна $7,9^{\circ}$, в Финском заливе $7,3-7,6^{\circ}$. Поверхностные воды максимально прогреваются в прибрежных районах обычно в июле, а в открытых в августе. Так, в августе средняя температура воды в Центральной Балтике $13-17^{\circ}$, в Рижском заливе $17-20^{\circ}$, в Финском заливе $16-18,5^{\circ}\left[{ }^{2}\right]$.

В качестве токсических загрязнителей мы выбрали четыре наиболее распространенных в морской воде вещества - три пестицида (п,п'ДДЕ, п,п'ДДД и п,п'ДДТ) и один бифенил (хлофен А-50). Эти хлорорганические углеводороды добавляли в свежие пробы морской воды. За начальные концентрации ппринимали п,п'ДДЕ - 0,9, п,п'ДДД - 0,5, п,п'ДДТ - 0,8 и ПХБ - 0,6 мкг/л и определяли их количества через $7,14,30$ и 105 сут после начала опыта.

Пробы воды (500 мл) дважды экстрагировали н-гексаном (100 мл), а экстракт очищали концентрированной серной кислотой. Разделение взвеси не проводили из тех соображений, что растворимые, а также адсорбируемые взвесью хлорорганические соединения способствуют заражению живых морских организмов.

Анализ проводили на хроматографе модели $3920 \mathrm{~B}$ с детектором электронного захвата фирмы «Перкин-Эльмер». Твердым носителем служил газ - хром Q с неподвижной фазой ДC-200+QF-1. Температура в испарителе, детекторе и колонке поддерживалась равной 220 , 325 и $190^{\circ}$ соответственно [3].

Анализ выделенных из воды хлорорганических углеводородов сопряжен с определенными трудностями, так как ПХБ представляет собой смесь веществ с различной степенью хлорирования. На газовой хро- 


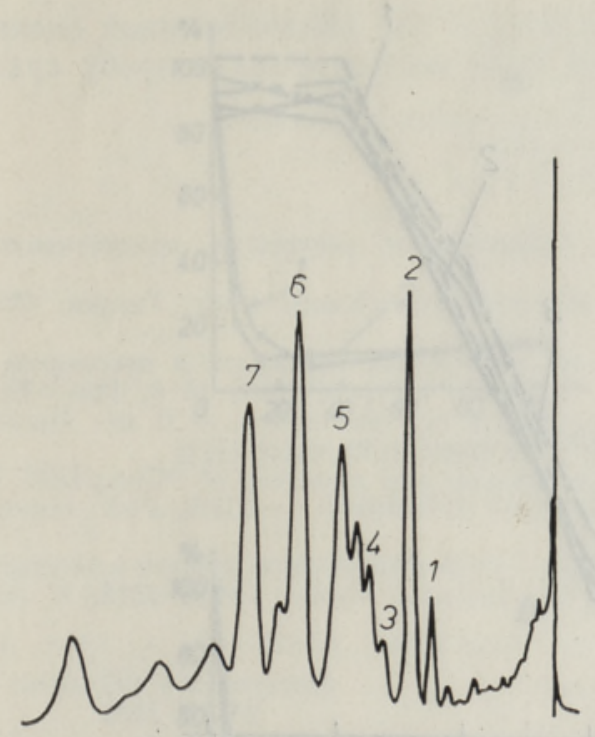

Рис. 1. Хроматограмма стандартного раствора ПХБ (хлофена А-50) в морской воде. Концентрацию ПХБ определяли суммированием пиков $1-7$.
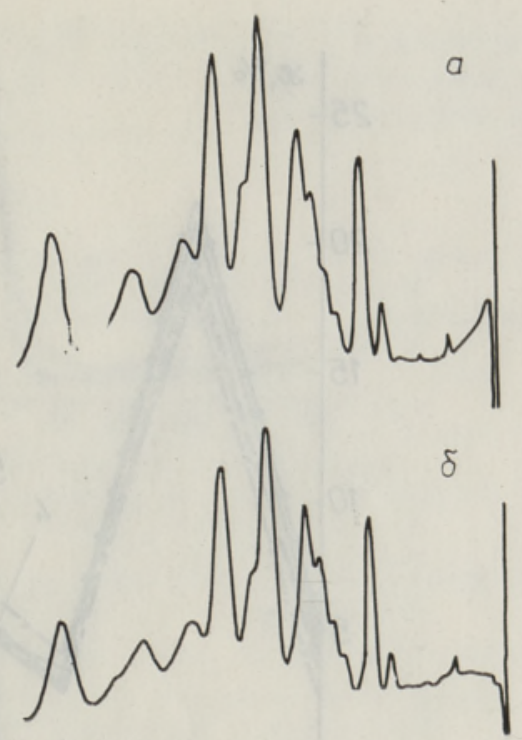

Рис. 2. Хроматограммы ПХБ через 1 (a) и 105 сут (б) хранения проб.

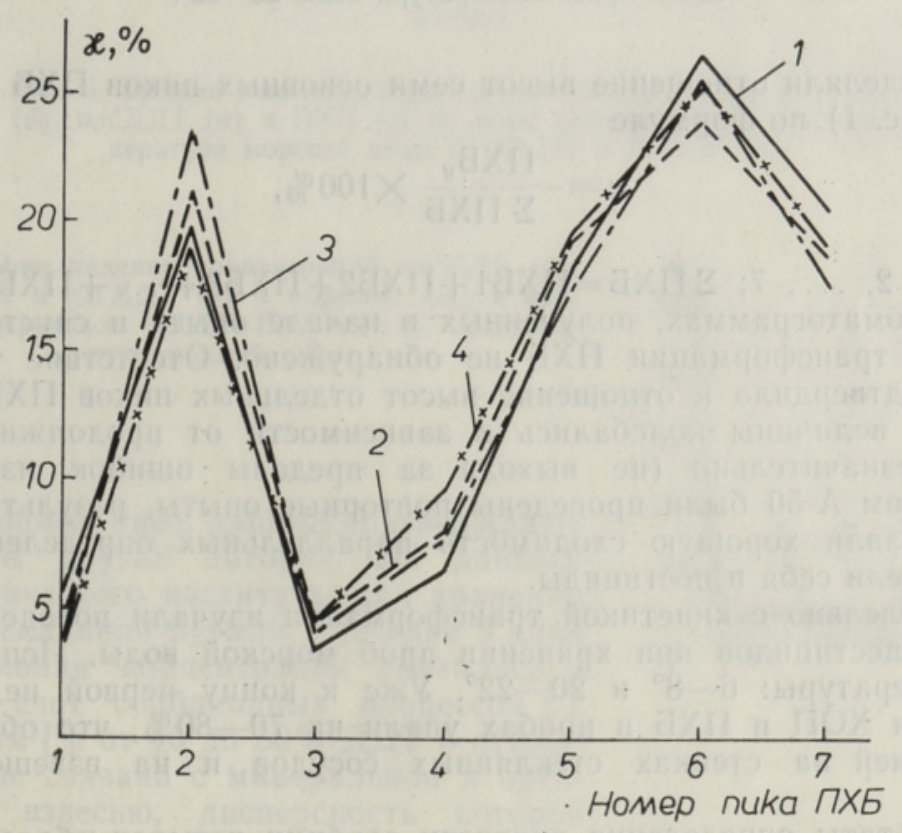

Рис. 3. Отношение высот семи основных пиков ПХБ через 1 (1), 2-7 (2), 3-14 (3) и 4-105 сут (4) хранения проб. Температура воды $6-8^{\circ}$.

матограмме ПХБ обычно наблюдается большое число пиков, из которых лишь часть совпадает с пиками пестицидов. Поэтому для разложения пестицидов пробу обрабатывали сначала 10\%-ным раствором едкого калия в метаноле, а затем хромовой кислотой.

При изучении кинетики трансформации ПХБ в морской воде Бал- 


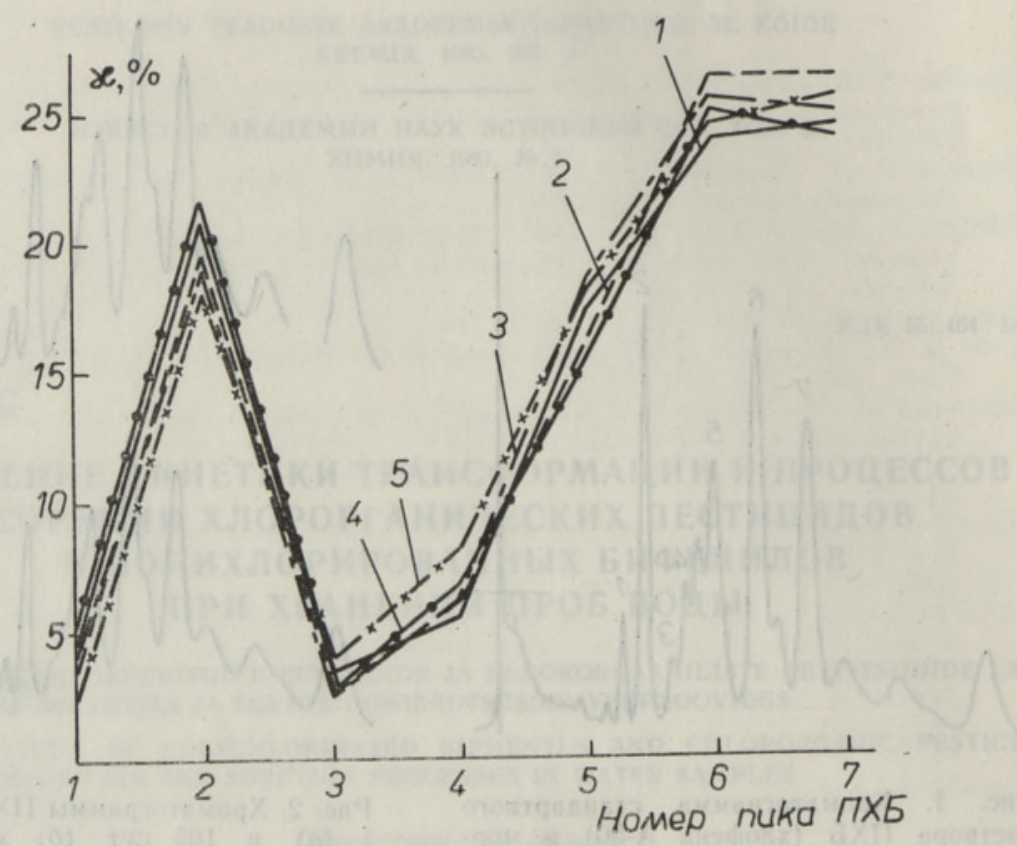

Рис. 4. Отношение высот семи основных пиков ПХБ через 1 (1), 2-7 (2), 3-14 (3), 4-30 (4) и 5-105 сут (5) хранения проб. Температура воды $20-22^{\circ}$.

тики определяли отношение высот семи основных пиков ПХБ (хлофена А-50) (рис. 1) по формуле

$$
x=\frac{\Pi Х Б_{y}}{\Sigma \Pi Х Б} \times 100 \%,
$$

где $y=1,2, \ldots, 7 ; \Sigma$ ПХБ= ПХБ1+ ПХБ2 + ПХБ3 $+\ldots+$ ПХБ7.

На хроматограммах, полученных в начале опыта и спустя 105 сут (рис. 2), трансформации ПХБ не обнаружено. Отсутствие трансформации подтвердило и отношение высот отдельных пиков ПХБ (рис. 3 и 4): их величины колебались в зависимости от продолжительности опыта незначительно (не выходя за пределы ошибок измерения). С хлофеном А-50 были проведены повторные опыты, результаты которых показали хорошую сходимость параллельных определений. Аналогично вели себя и пестициды.

Параллельно с кинетикой трансформации изучали поведение бифенилов и пестицидов при хранении проб морской воды. Использовали две температуры: $6-8^{\circ}$ и $20-22^{\circ}$. Уже к концу первой недели концентрации ХОП и ПХБ в пробах упали на $70-80 \%$, что объясняется их сорбцией на стенках стеклянных сосудов и на взвешенных веществах.

Результаты определения скорости сорбции четырех образцов хлорорганических углеводородов в природной морской воде представлены на рис. 5. Как видно, с повышением температуры от 6 до $20^{\circ}$ ускорение сорбции происходит только в начальной стадии эксперимента.

Процессы сорбции хлорорганических углеводородов исследовали и при совместном присутствии в воде ХОП и ПХБ. Обнаружено, что сорбция пестицидов совершается быстрее при наличии в воде ПХБ (рис. 6). В сорбции ПХБ такого различия не прослеживалось. Полученные результаты носят предварительный характер и требуют дальнейшего многостороннего изучения, 

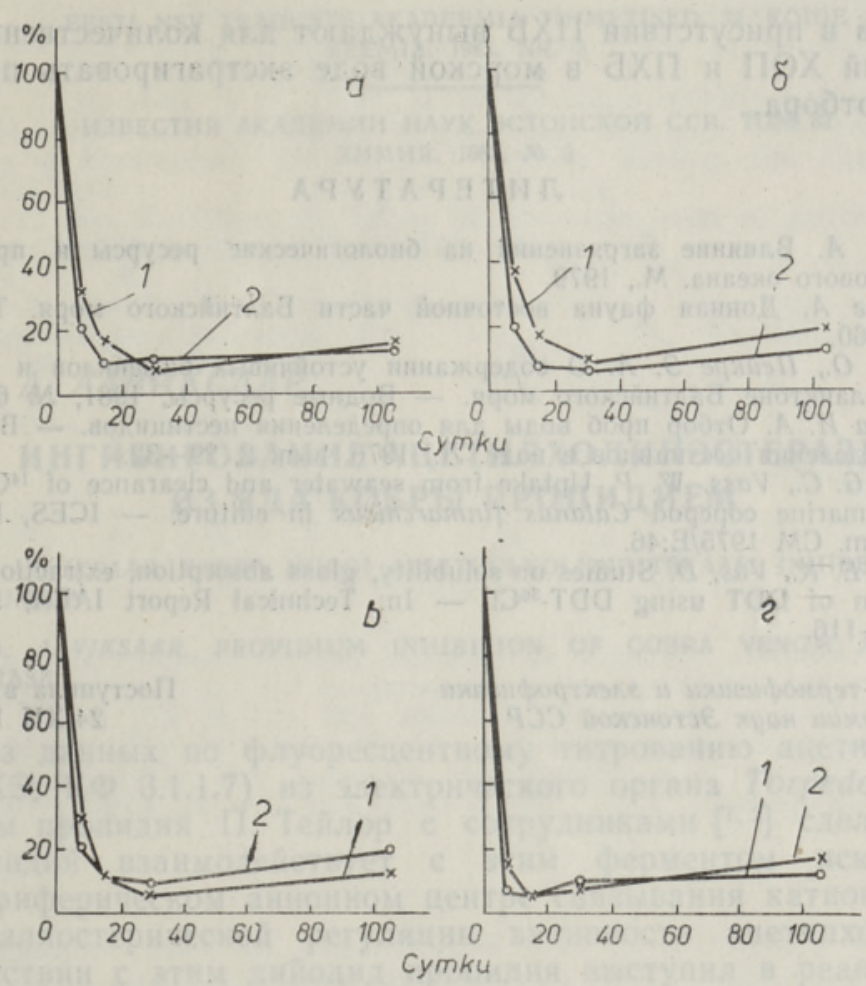

Рис. 5. График падения концентраций п,п'ДДД (a), п,п'ДДЕ $(б)$, п,п'ДДТ (в) и ПХБ (c) по мере хранения проб при температуре морской воды $6-8^{\circ}$ (I) и $20-22^{\circ}$ (2).

Рис. 6. График падения концентраций п,п'ДДЕ (I), п,п'ДДД (2) и п,п'ДДТ (3) в морской воде в присутствии бифеннлов (ДДТ : ПХБ $\approx 1: 1)$. Температура воды $6-8^{\circ}$.

Полученные нами данные подтверждают результаты других авторов. По данным Гидрохимического института, при хранении ДДТ в стеклянной бутыли в течение 5 дней его начальная концентрация снизилась в 5 раз за счет сорбционных процессов [ $\left.{ }^{4}\right]$.

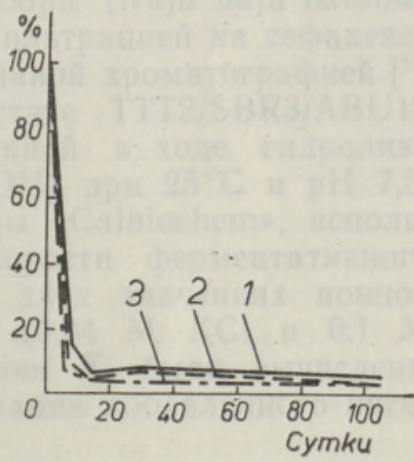
По данным [5], от 10 до $50 \%$ ДДТ в открытом океане связано с минеральной и органической взвесью, дисперсность которой превышает 0,2 мкм. В [6] показано, что через 20 сут после добавления в сосуды с морской водой около 0,8 мкг/л ДДт значительная часть его $(40-80 \%)$ адсорбируется на стенках.

\section{Выводы}

Общая тенденция убывания содержания хлорорганических веществ в пробах воды (из-за сорбционных процессов) в ряду п,п'ДДЕ $\rightarrow$ $\rightarrow$ п,п'ДДД $\rightarrow$ п,п'ДДТ $\rightarrow$ ПХБ (хлофен А-50) и ускорение сорбции 
пестицидов в присутствии ПХБ вынуждают для количественной оценки содержаний ХОП и ПХБ в морской воде экстрагировать пробу еразу же после отбора.

\section{ЛИТ Е РА Т У Р А}

1. Патин С. А. Влияние загрязнения на биологические ресурсы и продуктивность Мирового океана. М., 1979.

2. Ярвекюльг А. Донная фауна восточной части Балтийского моря. Таллин, 1979, $27-60$.

3. Роотс О. О., Пейкре Э. А. О содержании устойчивых бифенилов и пестицидов в зоопланктоне Балтийского моря. - Водные ресурсы, 1981, № 6, 182-186.

4. Гончарова И. А. Отбор проб воды для определения пестицидов. - В кн.: Методы определения пестищидов в воде. Л., 1976, вып. 2, 29-32.

5. Harding, $G$. C., Vass, $W$. P. Uptake from seawater and clearance of ${ }^{14} \mathrm{Cl}-\mathrm{p}, \mathrm{p}$ 'DDT by the marine copepod Calanus finmarchicus in culture. - ICES, Fish. Improv. Comm. CM 1975/E:46.

6. Duursma, E. K., Vas, D. Studies on solubility, glass absorption, extraction and evaporation of DDT using DDT- ${ }^{36} \mathrm{Cl}$. - In: Technical Report IAEA, 1974, N 163, $114-116$.

Институт термофизики и электрофизики Академии наук Эстонской ССР

Поступила в редакцию 24/XII 1982 